\title{
Editorial
}

\section{Interdisciplinary Applications of Physics in Economics and Finance}

The current topical issue continues a tradition of interdisciplinary EPJB focus sections in which all presented papers have to pass EPJB's regular peer-reviewing process with at least two independent referee reports. In light of the global financial crisis it is quite befitting that all contributions in this topical issue deal in one way or another with financial markets, although submissions have not been screened whatsoever in this respect. On the other hand, the focus on finance is not overly surprising either, since this is the traditional stronghold of the econophysics literature.

Taking stock of econophysics research in finance (what Eugene Stanley once coined phynance, i.e. the study of financial data with tools and methods originating in statistical physics), it seems fair to say that the field has made significant contributions to our understanding of financial markets and especially their statistical features over the past two decades, an understanding that goes well beyond the insights that most of the traditional economics and finance literature has produced over a period about twice as long. While the traditional approach has mostly been focusing on the efficient market hypothesis and the normative implications of incomplete or imperfect markets, phynance has focused on the statistical distributions of financial returns and trading volumes, their autocorrelations, their crosscorrelations, and the correlations among a broad spectrum of financial assets. The most prominent results that have been established so far concern the power law-like tails of the return and volume distributions, and the long memory property of financial volatility, often loosely referred to as volatility clustering.

It is undoubtedly true that econometricians have discovered many of these regularities before phynance was even conceived, and the respective econometricians certainly deserve appropriate credit for it, yet their findings have had no impact on the behavioral modeling in traditional models that typically start from the rational expectations hypothesis $(\mathrm{REH})$ and are inconsistent with the statistical features of real financial markets. The interdisciplinary approach, on the other hand, has always considered the replication of the statistical regularities as a minimum requirement in model building. In this context, it is particularly the order-book driven and agent-based herding models that have substantially enhanced our understanding of the stylized facts in different but complementary ways; after all, the large gaps in order books or the lack of liquidity that lead to large price fluctuations are ultimately due to the herding tendencies of market participants. Admittedly all that glitters is not gold, as witnessed by the large number of criticality-inspired physical models in phynance, which are hardly convincing from a social science point of view, yet it is hard to see why even those would be any less relevant than REH models, or would contain less behavioral insights than econometric time series models.

The conundrum for economists dates back at least to Ludwig von Mises' and Friedrich August von Hayek's work during and after the Socialist Calculation Debate, who forcefully argued against the feasibility of central economic planning. It was Hayek in particular, with his distinction between economy and what he called catallaxy, who emphasized that a system of free market prices leads to the emergence of spontaneous order, and is the most efficient way to "self-organize" dispersed and tacit information in such a way as to prevent shortages or gluts of goods. His reasoning is still at the heart of many arguments advocating uncontrolled and pure free markets, and anyone recalling the difficulties and waiting time involved in purchasing coffee, sugar, or vegetable oil in socialist economies will surely agree that a system of free market prices is vastly superior in its organizational capabilities compared to a system of central planning. As far as free financial market prices are concerned, however, the statistical evidence, everyday experience, and certainly every financial crisis also teach us that financial prices undergo swings that are many orders of magnitude larger than the swings in any related fundamental variable. So why do financial returns exhibit such behavior, while changes in 
daily prices for haircuts, TV sets, or cars do not-unless one considers hyperinflation regimes? Essentially, financial assets decouple real or physical assets from promises about the future value or delivery of these assets - just as money is a promise about the inherent value of a basket of goods against which money can be exchanged. During "normal" market periods, when confidence is at "normal" levels, such promises are more or less anchored by the movements and knowledge of underlying fundamentals. But promises, or "expectations" concern the future, and the human mind is all to prone to biased perceptions of an unknowable future and to narrative fallacies of the past, giving rise to large swings in expectations regarding the future value of these promises, whether they relate to equities, bonds, derivatives, or the value of fiat money. This implies that processes of social interaction, like herding tendencies or full-blown manias, can easily lead to enormous swings in financial prices that are hard to reconcile with any notion of rationality, much less the strict economic one.

From this point of view, financial crises are in the end caused by agents' expectations about the future value of financial assets, while the particular assets in question are of course different in every crisis. The colloquial truism that financial crises are evidence of "shockingly low standards in high places" is not inconsistent with such a notion. Agents in the trading or structuring departments of financial institutions are always subject to peer pressure through the process of benchmarking: an agent who believes, for instance, that asset-backed commercial paper is currently mispriced and its value unsustainable in the long-run will be let go in the short-run if, instead of jumping on the bandwagon, she or he invests in or constructs "safer" securities with a markedly lower return. And there is, by the way, very little that regulators can do about this, short of abandoning free financial markets altogether, which in spite of the huge costs associated with financial crises does not seem to be a feasible option.

Ultimately, we believe the primary research questions should concern the nature of interactions among financial market participants, since it is those that are responsible for their striking non-Gaussian appearance. The aforementioned benchmarking in the financial industry is merely one such mechanism, while various institutional factors, like the well-documented concentration in the banking sector or the structure of managed fund investment, can lead to the coordination of trading positions that contribute to the creation of systemic risk in financial markets. Regulators would probably be well advised to enforce rules aimed at increasing the transparency of financial institutions' and their counterparties' positions, which would allow for a mapping of the network structure of contracted obligations that is crucial for the management of systemic risks. In fact, interdisciplinary economists and physicists have started to investigate the network structure among financial market participants quite some time ago, yet the available data have so far been only of limited utility for the purpose of risk management due to their incompleteness, a feature that can only be remedied by tighter international standards of supervision. In the end, at least from a network perspective, transparency is much more important for regulation and crisis prevention than the practiced mechanical rules of the various Basel Accords that center around capital requirements.

Finally, the editorials of EPJB's topical issues on research in "econophyics" have also become somewhat of a traditional outlet to comment on the current state and development of the econophysics community in general, and while we have (maybe overly) praised the interdisciplinary contributions of phynance, it is fair to say that contributions to the major macroeconomic issues of growth, inflation, and unemployment are still in its infancy. One reason for this is obviously that traditional macroeconomic time series, typically being recorded at quarterly or at best monthly frequencies, provide very few data compared to financial markets and thus lead to less reliable statistics. But this should not prevent the community from increasing research efforts into the central macroeconomic issues because traditional economics has contributed very little to our understanding of these, while the potential pay-offs to society are huge.

The Guest Editors

Simone Alfarano, Thomas Lux and Mishael Milaković 